\title{
Economic analysis of low-carbon economy and policy suggestions
}

\author{
Hongjun $\mathrm{Cao}^{1, \mathrm{a}}$, Guixin Han ${ }^{2, \mathrm{~b}}$ \\ ${ }^{1}$ School of Management, Ocean University of China, Qingdao, China \\ 2 School of Management, Ocean University of China, Qingdao, China

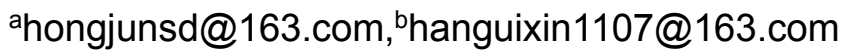

\begin{abstract}
Keywords: low-carbon economy; economic analysis; Kuznets curve; tunnel effect
Abstract. Based on the finiteness of resources and the seriousness of environmental pollution, and considering that China is a large energy consuming country and a large country of carbon dioxide emissions, it is necessary to develop low-carbon economy. This paper analyses the application of environmental Kuznets curve in low-carbon economy, and introduces environmental protection technology. This paper analyzes the path influence on the environmental Kuznets curve through the tunnel effect, and analyzes the economic theory of low-carbon economy. And put forward the policy suggestions to promote the development of low carbon economy in China.
\end{abstract}

\section{Introduction}

Since the reform and opening up, China's economy has grown rapidly. But behind the prosperity of the economy is accompanied by a huge resource and environmental cost. Moreover, it also aggravates the contradiction between economic development and ecological environment protection. Based on this background, low-carbon economy is concerned by various countries (regions). Liu Huajun et al. (2011) studied the environmental Kuznets curve of CO2 emissions in China based on the empirical estimation of time series and panel data. It confirmed that the unit GDP emissions and per capita income were consistent with the inverted $U$ type environmental Kuznets curve. Cheng Dongxiang et al. (2016) studied the relationship between technological innovation and low-carbon economic growth, and introduced the grey relational analysis method in VAR model, which confirmed the contribution of technological innovation talents investment to low-carbon economic growth rate. Ni Chaojun, Ma Xueqin (2017) also empirically studied the relationship between financial development, technological progress and low-carbon economy by using the VAR model. There are also some studies using the data envelopment analysis (DEA) method to construct a low-carbon economic evaluation index system (Liu Junyue and other 2016).

The development of low-carbon economy has become inevitable, but the related research on low carbon economy is based on a deep understanding of low-carbon economy. Economic analysis can analyze the nature of the problem by certain assumptions. The low-carbon economy is analyzed from the economic point of view to provide theoretical support for the development of low-carbon economy.

\section{Environmental Kuznets curve under low-carbon background}

\section{Climate change is a new environmental problem}

At present, global climate change has become a key concern in the world, and has caused many negative impacts on the ecosystem. For example, the melting of the Arctic and Antarctic ice sheets has led to the continuous rise of sea level. Many coral reef ecosystems are also dying away. It also has a certain impact on the forest system (Bai Guanghui et al., 2015).

There are not many differences between climate change and traditional environmental problems in many ways. But climate change also has its characteristics. Climate change is more complex than traditional environmental pollution problem, because it is not only a simple environmental problem, but also involves many aspects such as politics, economy and culture. (Wu You, 2015) In addition, the traditional environmental pollution is mostly regional environmental problems, and climate 
change is different. Carbon dioxide is evenly distributed around the world and has an impact on all countries around the world. From the adverse effects of climate change on the ecological environment, it can be seen that climate change is a new global environmental problem.

\section{Environmental Kuznets curve}

The environmental Kuznets curve (EKC) is one of the representative theories to explain the causes of the current environmental change. Therefore, we believe that the environmental Kuznets curve can be applied to explain the current climate change problems and the development of low-carbon economy.

The environmental Kuznets curve hypothesis shows that, at the early stage of social economic development, the development of economy has a great negative impact on the environment, that is to say, economic growth leads to environmental degradation. But when the economy develops to a certain stage, the environmental quality has a positive correlation with the economic development, that is to say, with the economic growth, the environment will be improved gradually. Therefore, this hypothesis is that the relationship between environmental quality and economic growth is inverted U - shaped, ${ }^{1}$ as shown in Figure 1.

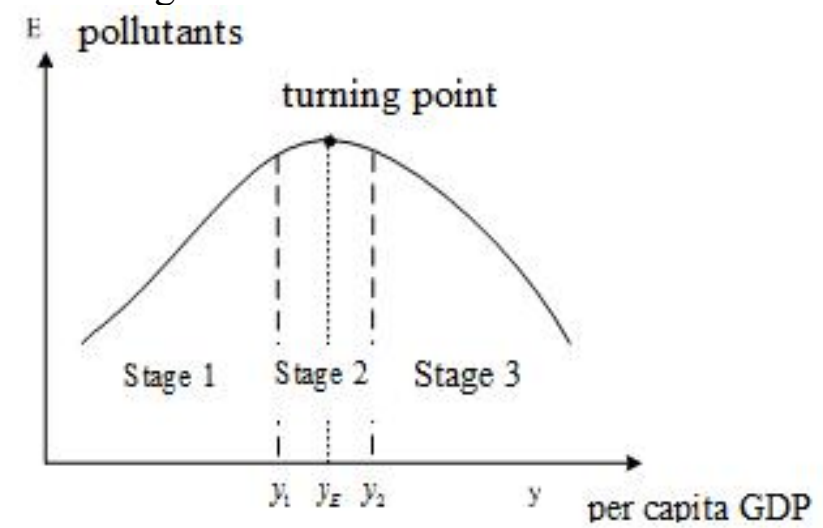

Figure 1 Environmental Kuznets curve

As can be seen from Figure 1, the EKC inverted U curve can be divided into three stages: Stage 1 is the early stage of economic development. In this stage, with the development of the economy, the environment has been gradually deteriorated. Stage 2 is the turning stage. At this stage, with the development of economy, the speed of environmental deterioration has been slowed down, and the environment has begun to improve after a certain stage of economic level. Stage 3 is the coexistence of steady economic growth and environmental improvement. At this stage, with the continuous development of economy, the ecological environment has been gradually improved, and the environmental pressure has been reduced.

\section{The basic theory of EKC hypothesis}

Suppose that in the year of $t$, the environment related output $\left(\mathrm{S}_{\mathrm{t}}\right)$ in the process of material exchange between the environment and the economy is the product of population $\left(\mathrm{P}_{\mathrm{t}}\right)$ and the per capita environmental demand $\left(\mathrm{U}_{\mathrm{t}}\right){ }^{2}$ The expression form is

$$
\mathrm{S}_{\mathrm{t}=} \mathrm{P}_{\mathrm{t}} \times \mathrm{U}_{\mathrm{t}}
$$

$\mathrm{S}_{\mathrm{t}}$ is output. It means that environmental resources return to the material and energy flow in the environment through the economic production activities of human beings. It contains the material (M) that put into the production activities and wastes (W) that are discharged into the environment by economic systems. $M$ represents the environmental pressure of exhaustion of resources. W represents the environmental pressure of environmental pollution damage. Thus $\mathrm{S}_{\mathrm{t}}$ represents the

\footnotetext{
${ }^{1}$ Stern D I. Progress on the Environmental Kuznets Curve?[J]. Environment \& Development Economics, 1998, 3(2):173-196.

2 Bruyn S M D, Opschoor J B. Developments in the throughput-income relationship: theoretical and empirical observations[J]. Ecological Economics, 1997, 20(3):255-268.
} 
total environmental pressure.

Besides, subdivide $U_{t}$ into the product of per capita income $\left(\mathrm{y}_{t}\right)$ and environmental pressure $\left(\mathrm{E}_{\mathrm{t}}\right)$ caused by unit income. The formula (1) is further expressed as

$$
\mathrm{S}_{\mathrm{t}}(\mathrm{M}, \mathrm{W})=\mathrm{P}_{\mathrm{t}} \times \mathrm{y}_{\mathrm{t}} \times \mathrm{E}_{\mathrm{t}}(\mathrm{M}, \mathrm{W})
$$

The resources required to be input to get unit income represents the material intensity of economic activity $\left(\mathrm{M}_{\mathrm{t}} / \mathrm{Y}_{\mathrm{t}}\right)$. The pollution caused by unit income represents the pollution intensity of economic activities $\left(\mathrm{W}_{\mathrm{t}} / \mathrm{Y}_{\mathrm{t}}\right)$. $\mathrm{Y}_{\mathrm{t}}$ is the total material welfare (total income). The formula for $\mathrm{Y}_{\mathrm{t}}$ is $\mathrm{Y}_{\mathrm{t}}=$ $\mathrm{P}_{t} \times \mathrm{y}_{\mathrm{t}}$. And then the definition of "reduced materialistic effects" is that the material intensity reduced as time goes on. The definition of "reduced pollution effects" is that the pollution intensity reduced with time lapse. If $\mathrm{S}_{\mathrm{t}}$ is a function of $\mathrm{M}$ only, the formula (1) can be rewritten as

$$
\mathrm{S}_{\mathrm{t}}(\mathrm{M})=\mathrm{Y}_{\mathrm{t}} \times \mathrm{m}_{\mathrm{t}}
$$

$\mathrm{Y}_{\mathrm{t}}$ is the total income, and $\mathrm{m}_{\mathrm{t}}$ is the material intensity in time of $\mathrm{t}$.

Derivation on both sides of formula (3) is $\dot{\mathrm{S}} \mathrm{t} / \mathrm{S}_{\mathrm{t}}=\left(\dot{\mathrm{Y}} \mathrm{t} / \mathrm{Y}_{\mathrm{t}}\right) \times\left(\dot{\mathrm{m}} \mathrm{t} / \mathrm{m}_{\mathrm{t}}\right)$

It can be seen from the formula (4), in the process of economic growth, there will be two forms, weak reduced materialistic effects and strong reduced materialistic effects. When $\dot{\mathrm{m}}<0$ and $\dot{\mathrm{S}} \gg 0$, the material intensity decreases. But the total material consumption does not decrease, which shows weak reduced materialistic effects. But when $-\dot{\mathrm{m}} \mathrm{t} / \mathrm{m}_{\mathrm{t}}>\dot{\mathrm{Y}} \mathrm{t} / \mathrm{Y}_{\mathrm{t}}$, the total material consumption decreases with the change of time, which is called the strong reduced materialistic effects.

The concept of separation between environmental pressure and economic growth includes reduction of materialization and reducing contamination. It refers to the process of reducing the impact of the total economic activity on the environment. Separation can be described as weak separation and strong separation. The EKC hypothesis is based on these two strong separations.

\section{Tunnel effect}

If the assumption is to consider the environmental impact and environmental governance technology, the production function is $\mathrm{Y}=\mathrm{F}\left(\mathrm{K}, \mathrm{L}, \mathrm{E}, \mathrm{T}_{\mathrm{E}}\right)$

$\mathrm{K}$ represents capital input in production and $\mathrm{L}$ represents labor input in production. So, its inverse function $\mathrm{E}=\mathrm{F}^{-1}\left(\mathrm{Y} ; \mathrm{K}, \mathrm{L}, \mathrm{T}_{\mathrm{E}}\right)$ is the analytic representation of the environmental Kuznets curve.

By taking the formula (5) to the complete differential, we can obtain

$$
d Y=(\partial Y / \partial K) \times d K+(\partial Y / \partial L) \times d L+(\partial Y / \partial E) \times d E+\left(\partial Y / \partial T_{E}\right) \times d T_{E}
$$

Divide both sides of formula (6) by Y, we can get the following formula

$$
\begin{aligned}
& \mathrm{dY} / \mathrm{Y}=(\partial \mathrm{Y} / \partial \mathrm{K}) \times(\mathrm{K} / \mathrm{Y}) \times(\mathrm{dK} / \mathrm{K})+(\partial \mathrm{Y} / \mathrm{HL}) \times(\mathrm{L} / \mathrm{Y}) \times(\mathrm{dL} / \mathrm{L})+(\partial \mathrm{Y} / \partial \mathrm{E}) \times(\mathrm{dE} / \mathrm{Y})+\left(\partial \mathrm{Y} / \partial \mathrm{T}_{\mathrm{E}}\right) \\
& \times\left(\mathrm{dT}_{\mathrm{E}} / \mathrm{Y}\right) .
\end{aligned}
$$

The contribution rate of capital is ${ }^{\Theta}$, then the contribution rate of labor is $1-{ }^{\ominus}$, Assign $\mathrm{w}=\Theta \times(\mathrm{dK} / \mathrm{K})+(1-\Theta) \times(\mathrm{dL} / \mathrm{L})$ we can get formula $(8)$

$$
\partial \mathrm{Y} / \partial \mathrm{E}=\left[\mathrm{dY} / \mathrm{Y}-\mathrm{w}-\left(\partial \mathrm{Y} / \partial \mathrm{T}_{\mathrm{E}}\right) \times\left(\mathrm{dT}_{\mathrm{E}} / \mathrm{Y}\right)\right] /(\mathrm{dE} / \mathrm{Y})
$$

It is known from formula (8) that the impact of environmental protection technology on the path of Kuznets curve depends on the contribution rate of environmental protection technology. On 
the one hand, the contribution of environmental protection technology to GDP is positive, that is to say $(\partial \mathrm{Y} / \partial \mathrm{E}) \times\left(\mathrm{d} \mathrm{T}_{\mathrm{E}} / \mathrm{Y}\right)>0$. However, the contribution of environmental factors to the production function is negative, so $d Y / Y-w<0$. Therefore, environmental technology promotes economic growth, that is to say $d Y / Y-w-(\partial Y / \partial T E) \times(d T E / Y)<0$. On the other hand, environmental protection technology reduces environmental load. This makes $\mathrm{dE}>0$ ( or $\mathrm{dE} \rightarrow 0$ ), which means $\partial \mathrm{Y} / \partial \mathrm{E}<0(\partial \mathrm{Y} / \partial \mathrm{E} \rightarrow \infty)$. This shows that the Kuznets curve tends to decline or stabilize.

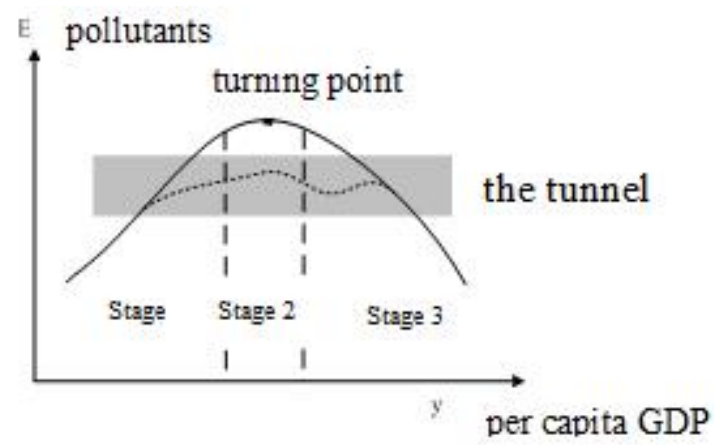

Figure 2 tunnel effect

The above analysis shows that with the introduction of technological progress into economic growth, the growth path of the horizontal per capita GDP will continue and the speed of environmental pollution will gradually slow down. After reaching the peak in a short time, it enters the third stage and realizes the ideal and sustainable development. This is the tunnel effect, which has set up a shortcut to economic development on the basis of environmental protection, as shown in Figure 2.

\section{Conclusions}

At present, the development of low-carbon economy in China is still in the exploration period. It is necessary to follow the trend of the world economy, seize the opportunity and promote the development of the low-carbon economy in the future.

\section{Upgrading and optimizing the industrial structure}

Through the development and application of new technology, the industrial structure will be promoted to a more reasonable direction, thus reducing energy consumption and promoting the development of low carbon economy. Relying on the continuous low-carbon technology, we should carry out low-carbon and environment-friendly production concept, improve the quality and added value of product structure, increase the proportion of products with high added value, and promote the continuous and healthy development of low carbon economy.

\section{Enhancing the independent innovation of low-carbon technology}

The core of the development of low-carbon economic model is low-carbon technology innovation. We should provide a good institutional environment and market mechanism for the independent innovation of low carbon technology. Based on the national conditions of coal as the main source of energy in China, the innovation of coal cleaning and utilization related technologies should be emphasized. In addition, we should strengthen technology innovation such as energy saving and emission reduction technology, new energy technology, renewable energy technology, carbon capture, carbon sequestration technology and so on. It provides a strong guarantee for the development of low carbon economy.

Strengthen international cooperation and draw lessons from foreign advanced experience

Global climate change is the responsibility of all countries and regions, and international cooperation is the only way to solve global climate change. As a developing country, there is still a 
huge gap in low-carbon technology level compared with developed countries. We should be guided by the concept of sustainable development, and learn from foreign successful experience and carry out bilateral, multilateral and regional cooperation actively, speed up the achievement transformation and technology introducing, and continue to promote the healthy development of China's low-carbon economy.

\section{Acknowledgements}

This work was financially supported by the National Social Science Fund later funding project (11FJY007).

\section{References}

[1] Bruyn S M D, Opschoor J B. Developments in the throughput-income relationship: theoretical and empirical observations[J]. Ecological Economics, 1997, 20(3):255-268.

[2] Stern D I. Progress on the Environmental Kuznets Curve?[J]. Environment \& Development Economics, 1998, 3(2):173-196.

[3] CHENG Dongxiang, ZHU Hong, CHEN Jing, ZHAO Fanghua. Relationship between Technology Innovation and Low Carbon Economy Growth of Nanjing on the Basis of Grey Method and VAR Model [J]. Ecological Economy, 2016, 32(10):62-66.

[4] NI Chaojun, MA Xueqin. An Empirical Study on the Relationship among Financial Development, Technological Progress and Low Carbon Economy Dynamic Verification Based on Panel VAR Model [J]. Ecologial Economy, 2017, 33(2):41-44.

[5] LIU Junyue, WANG Le, SU Ying, WANG Haiyun. Research on the Efficiency of Chongqing Low-Carbon Economy Based on DEA [J]. Journal of Chongqing University (Social Science), 2016, 30(7):44-51.

[6] LIU Huajun, YAN Qingyue, SUN Riyao. Empirical Estimation of Environment Kuznets Curve of Carbon Dioxide Emissions in China [J]. China Forum on Science and Technology 2011(4):108-113.

[7] BAI Guanghui, WU Rentana. The impact of global climate change on Forests [J]. Agricultural science and technology, 2015(9).

[8] WANG You. Research on the development model and path of low carbon economy in Jiangsu under the background of climate change [D]. Nanjing University of Information Science \& Technology, 2015. 